\title{
Literatura e representações da escola pública de horário integral*
}

\author{
Lúcia Velloso Maurício \\ Universidade do Estado do Rio de Janeiro, Faculdade de Formação de Professores \\ Universidade Estácio de Sá, Mestrado em Educação
}

\section{Da escola-parque aos centros integrados de educação pública}

Este trabalho faz um confronto entre o que se depreende da literatura produzida entre 1983 e 2001 sobre a escola pública de horário integral e a representação social que usuários e trabalhadores construíram a respeito dela. O tema se originou do fato de o estado do Rio de Janeiro assistir, em dois momentos nos últimos 20 anos, tanto à implantação quanto ao desmonte da escola pública de horário integral com base no argumento de haver ou não demanda para essa escola. Optou-se por contrapor aos argumentos da literatura as motivações a respeito do que mobilizaria as classes populares para a escola pública de

* Artigo elaborado a partir da pesquisa realizada para a tese Escola pública de horário integral: demanda expressa pela representação social, apresentada à Faculdade de Educação da UFRJ em setembro de 2001, sob orientação do professor Tarso Bonilha Mazzotti. horário integral. Assim, além de levantada a literatura significativa que discutiu a implantação desta escola no Rio de Janeiro, foi verificado, num momento em que a escola pública de horário integral não constituía política de governo nem do estado nem do município do Rio de Janeiro, se existia demanda subjetiva potencial por esta escola.

Os Centros Integrados de Educação Pública (CIEPs), projetados por Oscar Niemeyer, foram construídos e implantados no estado do Rio de Janeiro nas duas gestões do governador Leonel Brizola, através do Programa Especial de Educação (I PEE, de 1983 a 1986, e II PEE, de 1991 a 1994). O Programa tinha como objetivo implantar uma proposta de educação pública em tempo integral para o ensino fundamental em 500 unidades escolares, que atenderia a um quinto do conjunto de alunos do estado. Esse projeto baseou-se no diagnóstico feito por Darcy Ribeiro (1986) de que a incapacidade brasileira para educar sua população ou alimentá-la devia-se ao caráter de nossa sociedade, enferma de desigualdade e de descaso por sua população. Com esta preocupação, propôs uma escola de horário integral, como a oferecida 
nos países desenvolvidos, que pudesse evitar que a criança proveniente de famílias de baixa renda fosse condenada ao abandono das ruas ou à falta de assistência em lares em que são chamadas a assumir funções de adulto para que os pais possam trabalhar, tendo sua infância suprimida.

A concepção pedagógica dos CIEPs buscava assegurar a cada criança de $1^{\mathrm{a}}$ a $4^{\mathrm{a}}$ série um bom domínio da escrita, da leitura e do cálculo, instrumentos fundamentais sem os quais não se pode atuar eficazmente na sociedade letrada. De posse deles, a criança tanto poderia prosseguir seus estudos escolares como aprender por si mesma, livre, por esse aspecto, da condenação à exclusão social e habilitada ao exercício da cidadania. Outro princípio orientador era o respeito ao universo cultural do aluno no processo de introdução da criança no domínio do código culto. A escola devia servir de ponte entre a cultura do aluno, que sabe fazer muitas coisas para garantir sua sobrevivência, e o conhecimento formal exigido pela sociedade.

Esta escola foi projetada para atender 600 crianças em turno único, além de 400 à noite, na educação juvenil. Durante o dia os alunos deveriam ter, além das aulas curriculares, orientação no estudo dirigido, atividades esportivas e recreativas, acesso à leitura de livros e revistas na biblioteca, de vídeos na sala para esse fim, e participação em eventos culturais. Como o projeto previa atendimento aos alunos provenientes de segmentos sociais de baixa renda, as escolas foram localizadas preferencialmente onde havia maior incidência de população carente. A assistência médico-odontológica, a alimentação e os hábitos de higiene eram desenvolvidos como condição para o atendimento em horário integral dos alunos deste segmento social.

A proposta de escola de horário integral não é nova no Rio de Janeiro. Houve experiências de escolas particulares religiosas, do passado e do presente, que ofereciam educação de alta qualidade à elite; e houve escolas particulares leigas, que existem ainda hoje, propondo-se a oferecer aprendizagem global a alunos provenientes das classes média e alta. ${ }^{1} \mathrm{Na}$ esfera pública, o Governo Carlos Lacerda, no antigo estado da Guanabara, entre 1961 e 1965, implantou o Projeto Piloto de Educação de Crianças da Favela em cinco escolas. Esse programa de educação em tempo integral abrangia, além do atendimento pedagógico, atendimento médico, psicológico e alimentar aos alunos, e assistência social às suas famílias.

Mais significativas para nosso estudo foram as experiências desenvolvidas, a partir do início dos anos de 1950 no Rio de Janeiro, antigo Distrito Federal, em cinco escolas públicas de $1^{\mathrm{a}}$ a $4^{\mathrm{a}}$ série. Sob coordenação, supervisão e apoio financeiro do Instituto Nacional de Estudos Pedagógicos (INEP), presidido na época por Anísio Teixeira, este projeto experimental constituiu campo de pesquisa aplicada segundo orientações curriculares diversas. No mesmo período, desenvolveram-se quatro ginásios públicos, primeiro segmento do ensino médio, com finalidade de qualificação profissional. Mas a fundamentação do projeto de educação integral nos CIEPs, de fato, origina-se nos mesmos argumentos que levaram Anísio Teixeira, com quem Darcy Ribeiro trabalhou longos anos, a inaugurar, em 1950, o Centro Educacional Carneiro Ribeiro, em Salvador, quando era secretário de educação do estado da Bahia:

A idéia tinha a sedução de todas as simplificações. [...] mas a simplificação teve forças para congestionar as escolas primárias com turnos sucessivos de alunos, reduzindo a educação primária não só aos três anos escolares de Washington Luís, mas aos três anos de "meios-dias" [...]. (Teixeira, 1994, p. 173)

É contra essa tendência à simplificação destrutiva que se levanta este Centro Popular de Educação. Desejamos dar, de novo, à escola primária, seu dia letivo comple-

1 Referência ao Colégio Sacre Coeur de Jesus e ao Colégio São Bento, religiosos, e à Escola Americana, no Rio de Janeiro e ao Centro Educacional de Niterói, leigos. 
to. Desejamos dar-lhe seus seis anos de cursos. E desejamos dar-lhe seu programa completo de leitura, aritmética e escrita, ciências físicas e sociais, artes industriais, desenho, música, dança e educação física. Além disso, desejamos que a escola eduque, forme hábitos, forme atitudes, cultive aspirações, prepare, realmente a criança para a sua civilização [...] técnica e industrial, difícil e complexa por estar em mutação permanente. E, além disso, desejamos que a escola dê saúde e alimento à criança, visto não ser possível educála no grau de desnutrição e abandono em que vive.

O centro, chamado de Escola-Parque, contava com quatro escolas-classe, de nível primário, com funcionamento em dois turnos, projetadas para mil alunos cada, e uma escola-parque, com sete pavilhões, destinados às chamadas práticas educativas, freqüentadas pelos alunos em horário diverso ao da escolaclasse, de forma que as crianças permanecessem o dia completo em ambiente educativo. A proposta era que esse conjunto funcionasse como centro de demonstração para a instalação de outros semelhantes no futuro. Na primeira versão das metas educacionais propostas pelo Programa Especial de Educação, que foram discutidas pelos professores públicos do Rio de Janeiro no chamado Encontro de Mendes, em 1983, até as expressões escola-parque e centro de demonstração foram utilizadas, com a perspectiva de funcionamento idêntico à proposta por Anísio Teixeira.

\section{O projeto dos CIEPs no contexto da redemocratização do país}

O Programa Especial de Educação (PEE), que implantou o horário integral em escolas públicas do Rio de Janeiro, foi gestado no período de retomada da democracia no Brasil. Época de intensa agitação política, com reorganização de entidades representativas da sociedade civil, por um lado, e atentados da direita, por outro: entre 1978 e 1982, fim da censura prévia e do AI-5; Lei da Anistia e retorno dos exilados; destruição da sede da UNE e atentado do Riocentro; eleição direta para governadores, após 18 anos. $\mathrm{Na}$ área da educação, houve greve de professores da rede pública de ensino fundamental nos grandes estados brasileiros. Foram criados a Associação Nacional de Pós-Graduação em Educação (ANPEd), o Centro de Estudos de Educação e Sociedade (CEDES) e a Associação Nacional de Educação (ANDE), que realizaram a I Conferência Brasileira de Educação (CBE), em 1980, em São Paulo, com mil e quatrocentos participantes. Nesse ano, a reunião da Sociedade Brasileira para o Progesso da Ciência (SBPC), no Rio de Janeiro, teve como tema Ciência e educação na sociedade democrática. Em 1981 foi aprovada emenda constitucional que garantiu ao professor aposentadoria aos 25 anos de serviço; em 1982, a II CBE reuniu 2 mil participantes em Belo Horizonte, onde discutiram Educação: perspectiva na democratização da sociedade.

Os governos estaduais empossados em março de 1983 tiveram seus programas influenciados pelos debates que se travaram nos anos de 1978 a 1982. Todos os partidos recém-criados tentavam consolidar sua linha política em diversas áreas, entre elas a de educação. No dia em que assumiu o governo do estado do Rio de Janeiro, Leonel Brizola, eleito pelo Partido Democrático Trabalhista (PDT), nomeou a Comissão Coordenadora de Educação e Cultura, presidida por Darcy Ribeiro, vice-governador e secretário de cultura, e integrada pelas secretárias de educação do Estado e do Município do Rio de Janeiro, Iara Vargas e Maria Yedda Linhares, respectivamente. Essa Comissão foi o órgão diretor do Programa Especial de Educação.

As diretrizes educacionais do Governo Leonel Brizola foram publicadas em duas versões: a educacional, em três blocos de teses que foram discutidos no Primeiro Encontro de Professores do Primeiro Grau da Rede Pública do Rio de Janeiro, ocorrido em Mendes; ${ }^{2}$ e o Plano Quadrienal de Educação, contido no

2 As teses, na versão original, foram publicadas em novembro de 1983 no jornal Escola Viva, n 1, enviado para cada professor de todas as escolas públicas do estado e do município do Rio de Janeiro. Todas as escolas pararam um dia para discuti-las, e 
Plano de Desenvolvimento Econômico e Social do Estado do Rio de Janeiro 1984-1987, aprovado sem emendas pela Assembléia Legislativa em 21 de dezembro de 1983. O pequeno intervalo de tempo entre estas publicações gerou suspeita de que a participação dos professores no encontro de Mendes tivesse objetivo de legitimação, e não de discussão das teses propostas (Mignot, 1988; Cunha, 1991).

No ano de 1984 foi publicado o orçamento para a construção dos Centros Integrados de Educação Pública. O lançamento dos CIEPs foi visto como plataforma política para a iminente candidatura de Leonel Brizola à presidência da República. O início das obras desencadeou rude debate entre Vanilda Paiva e Darcy Ribeiro no jornal Folha de S.Paulo ${ }^{3}$ a respeito do programa dos CIEPs, denominado pela primeira como a “escola-mamute" (Paiva, 1985) e revidado pelo segundo como "pedagogia vadia" (Ribeiro, 1985). Vários educadores posicionaram-se, aprofundando-se o fosso entre a academia e a política de implantação da escola pública de horário integral. Em 1983, a III CBE, que ocorreu em Niterói, no estado do Rio de Janeiro, organizada pelas instituições ANPEd, CEDES e ANDE, com presença de cinco mil participantes entre militantes partidários, sindicais e estudantes, deixa entrever o acirramento de posições. Seu tema, Da crítica às propostas de ação, é revelador: tanto pode ser lido como partindo das críticas para a formulação de propostas de ação, como discutindo as críticas às propostas de ação.

Em maio de 1985 o primeiro CIEP foi inaugurado, recebendo o nome de Tancredo Neves, presidente da República recém-falecido. Outras inaugurações colocaram os CIEPs no centro da campanha para prefeito do Rio de Janeiro. A vitória do PDT possibilitou a

elegeram dois representantes por escola para a fase regional do Encontro. Nova discussão, e cada região elegeu representantes, compondo um fórum de 100 professores para o Encontro final, ocorrido em Mendes; as teses reformuladas após o Encontro foram publicadas em dezembro de 1983 no jornal Escola Viva, no 2.

3 Posteriormente esses artigos foram publicados na revista Educação e Sociedade. continuidade da política em vigor, apesar da intensa campanha contrária efetivada pela mídia. Em 1984, a Comissão Coordenadora de Educação e Cultura havia enviado Falas ao professor a todos os profissionais dos CIEPs, publicação que, além de conter as teses de Mendes, apresenta a primeira descrição detalhada da proposta dos CIEPs. Em 1986, a campanha para governador e para a Assembléia Nacional Constituinte começou com o Plano Cruzado. Novamente o CIEP esteve presente, tanto no debate dos candidatos como na imprensa ou na greve dos professores da rede pública. O Partido do Movimento Democrático Brasileiro (PMDB) venceu eleição para governador em 22 estados, inclusive no Rio de Janeiro, onde Darcy Ribeiro, idealizador dos CIEPs, perdeu. O Plano Cruzado encerrou-se seis dias após a eleição.

Darcy Ribeiro editou O livro dos CIEPs, descrição completa do I PEE (Ribeiro, 1986). Cavalieri (s/d.), em estudo a respeito desta obra, afirma que ela faz um diagnóstico essencialmente político e não técnico da educação pública brasileira, e que propõe um currículo comprometido ideologicamente com a transformação social. O horário integral aparece como essencial no processo de aprendizagem, e se diferencia de um semi-internato por ter justificativa estritamente pedagógica: a educação integral prevê a socialização, a instrução escolar e a formação cultural, vista como parte essencial do processo de aprendizagem e não como adereço, tornando-se a escola espaço social privilegiado para a formação do cidadão. O currículo apresenta diferentes origens filosóficas, refletindo as diversidades do pensamento educacional brasileiro.

O debate sobre a extensão do tempo diário de escolarização acirrou-se tanto durante a campanha para governador que a Fundação Carlos Chagas, considerando que as discussões a respeito dessa proposta caminhavam para a defesa de interesses de grupos, decidiu fazer um estudo sistemático a respeito dos CIEPs no Rio de Janeiro e do Programa de Formação Integral da Criança (PROFIC) em São Paulo. ${ }^{4}$ Em fe-

4 Convênio do governo do estado de São Paulo com as prefeituras, para repasse de verbas com finalidade de oferecer às 
vereiro de 1987, quando os governos que implementaram esses projetos deixavam o poder, foi realizado o Seminário denominado Escola pública de tempo integral: uma questão em debate, para o qual foram convidados especialistas que deveriam desenvolver três temas propostos e produzir textos específicos para a discussão em grupo fechado. O Seminário, primeiro momento do estudo, tinha dois objetivos (Paro et al., 1988c): complementar o incipiente referencial teórico sobre o assunto e levantar questões sobre o tema numa perspectiva teórico-prática. $\mathrm{O}$ segundo momento foi o trabalho de campo, com enfoque qualitativo. Os resultados do seminário levaram à deliberação de recorrer a três fontes: discursos oficiais a respeito de cada projeto; observações diretas em uma unidade de cada projeto; entrevistas com profissionais, alunos, pais de alunos e outros envolvidos na realização dessas experiências.

Esse Seminário alcançou o objetivo de contribuir para o desenvolvimento do referencial teórico sobre a escola pública de horário integral, pois os artigos "Direito ao tempo de escola", de Miguel Arroyo (1988) e "A escola de $1^{\circ}$ grau em tempo integral: as lições da prática”, de Zaia Brandão (1989), foram escritos para essa ocasião e tornaram-se literatura fundamental sobre o assunto. As comunicações produzidas no Seminário, acrescidas dos resultados da pesquisa de campo, deram origem aos artigos "A escola pública de tempo integral: universalização do ensino e problemas sociais" (Paro et al., 1988a) e "Viabilidade da escola pública de tempo integral" (Paro et al., 1988b), que vieram a integrar o último capítulo do livro Escola de tempo integral: desafio para o ensino público (Paro et al., 1988c). Este livro, apesar de se posicionar contrariamente à implantação da escola pública de horário integral, tornou-se leitura tão indispensável sobre o tema quanto $O$ livro dos CIEPs, tal a influência que exerceu sobre estudos posteriores.

crianças opções de atividades nos horários em que não estivessem na escola, aproveitando espaços comunitários disponíveis - às vezes, as próprias escolas.
Os novos governos estaduais tomaram posse em março. Moreira Franco, no Rio de Janeiro, convidou para cargos de destaque na Secretaria de Educação alguns intelectuais que, embora não tenham permanecido todo o período de governo, emprestaram seu nome para respaldar o discurso de igualdade de condições para todas as escolas, fazendo com que o horário integral, que requer ações específicas para seu desenvolvimento, fosse inviabilizado. Assim, a descontinuidade da verba para alimentação e a redução do quantitativo de professores levaram à supressão do horário integral nos CIEPs do Estado. Vários desses prédios foram utilizados para outras finalidades, inclusive para acolher desabrigados das enchentes. No município do Rio de Janeiro, a mudança de partido do prefeito, que deixou o PDT, levou a uma reorientação da política educacional, fazendo com que o horário integral deixasse de ser política de governo.

Em 1991, Darcy Ribeiro foi eleito para o Senado e Leonel Brizola para o segundo mandato de governador, pelo PDT. A partir de então, uma Secretaria Extraordinária foi criada pelo governo do estado do Rio de Janeiro, para que os CIEPs antigos fossem recuperados e novos fossem implantados; todos foram equipados e lotados com profissionais, de forma que pudessem atender aos três requisitos essenciais de uma escola popular eficaz:

Espaço para a convivência e as múltiplas atividades sociais durante todo o largo período da escolaridade, tanto para as crianças como para as professoras. O Tempo indispensável, que é igual ao da jornada de trabalho dos pais, em que a criança está entregue à escola. Essa larga disponibilidade de tempo possibilita a realização de múltiplas atividades educativas, de outro modo inalcançáveis, como as horas de Estudo Dirigido, a frequiência à Biblioteca e à Videoteca, o trabalho nos laboratórios, a educação física e a recreação. $\mathrm{O}$ terceiro requisito fundamental para uma boa educação é a Capacitação do Magistério. (Ribeiro, 1995, p. 22$)^{5}$

5 Foi criado o Curso de Atualização de Professores Bolsistas para a Escola de Horário Integral, para o qual eram seleciona- 
Em 1994, a meta de 500 CIEPs foi atingida, ampliando significativamente a oferta de matrículas em horário integral. Ainda neste ano, além de ter sido realizado o primeiro concurso do Estado para selecionar professores em regime de 40 horas, para trabalharem nos CIEPs, foi implantado, em prédios de CIEP adaptados para esta finalidade, no município do Rio de Janeiro, o projeto experimental chamado Ginásio Público, com currículo integrando programas de $5^{\mathrm{a}}$ a $8^{a}$ série do $1^{\circ}$ grau e $2^{\circ}$ grau, em seis anos, com opção entre horário integral ou parcial. Esta possibilidade de escolha pelo aluno, entre permanecer o dia inteiro na escola ou parte dele, foi fruto da avaliação feita do funcionamento do projeto no governo anterior, em que se verificou evasão dos CIEPs de segundo segmento do Ensino Fundamental.

Ainda em 1994, o candidato do PDT ao governo do estado, Anthony Garotinho, não destacou o programa dos CIEPs na campanha, evitando sua identificação com Leonel Brizola, que, candidato à presidência, teve votação pouco expressiva. Garotinho foi para o segundo turno, apoiado pelo Partido dos Trabalhadores (PT), mas perdeu para Marcelo Alencar, naquele momento filiado ao Partido da Social Democracia Brasileira (PSDB), cujo candidato à presidência, Fernando Henrique Cardoso, foi vitorioso como "pai" do Plano Real. Em 1995, assistiu-se novamente à desativação da rede de escolas de horário integral. O desmonte dessas escolas na gestão de Marcelo Alencar teve maior repercussão, tendo em vista que o quantitativo de escolas e de alunos era o triplo do que recebera Moreira Franco. Chegou a ser instalada uma CPI na Assembléia Legislativa para apurar as responsabilidades em relação à descontinuidade do projeto. Apesar de suas conclusões terem sido aprovadas por

dos professores que tinham concluído sua formação de $2^{\circ}$ grau entre 1987 e 1992. O curso, com duração de 1.600 horas, era organizado em módulos, realizado em cada CIEP, prescrevendo que as oito horas diárias de formação se dividissem em quatro horas de prática docente orientada e quatro horas de estudo teóricopedagógico através de programas de vídeo e material impresso. unanimidade na própria Comissão, jamais foram a plenário, por falta de interesse político.

Os CIEPs, chamados popularmente de Brizolões, começaram a ser estigmatizados como escolas para pobre a partir da campanha anti-brizolista que utilizou o discurso do próprio governador Leonel Brizola a respeito dessa escola. Esta representação foi largamente disseminada no decorrer dos governos Moreira Franco (1987-1991) e Marcelo Alencar (1995-1998), que deixaram os prédios de Oscar Niemeyer carimbados com a marca de política fracassada. A tese de uma arquiteta que estudou os significados que são incorporados aos prédios escolares é esclarecedora. Moussatché (1998) escolheu uma escola representante do projeto arquitetônico-pedagógico de três épocas da expansão de ofertas de vagas na rede escolar pública do Rio de Janeiro, sendo a última um CIEP. Analisando esses exemplos, mostrou como a escola, ao longo do século, foi utilizada por diversos grupos políticos, fazendo com que sua imagem se apresentasse como "objeto de desejo" da população por uns e "objeto de desprezo" por outros. Segundo a autora:

Ao assumirem o Poder, os grupos antagônicos ao governo anterior, entretanto, não se dedicam a mudar a "marca", como poderia-se esperar, mas abandonam completamente as políticas de expansão e, o que é mais grave, deixam de investir na manutenção dos prédios existentes. [...] E os prédios recém-construídos, assim como os mais antigos, deterioram-se até o momento em que, sem condições ambientais de utilização, passam a ser apresentados à população, através dos meios de comunicação, como "edificações obsoletas". (p. 186)

\section{Análises da implantação da escola pública de horário integral}

A produção escrita sobre a escola pública de horário integral pode ser vista em dois ciclos delimitados no tempo. As críticas, concentradas essencialmente no período de 1987 a 1991, trabalharam com dados do I PEE. As apreciações favoráveis começaram a 
surgir em 1990 e tiveram continuidade com dados do II PEE. Os críticos divulgaram suas idéias em revistas ou editoras de maior circulação que os defensores da escola de horário integral, cujas teses ou dissertações permaneceram, praticamente, restritas às universidades.

Antes de relacionar os aspectos positivos e negativos apontados por diversos autores a respeito do projeto dos CIEPs, é esclarecedor ilustrar o cenário da época. No artigo "A escola de $1^{\circ}$ grau em tempo integral: as lições da prática”, Zaia Brandão (1989) expõe sua relutância em participar do seminário promovido pela Fundação Carlos Chagas em 1987, tal o clima "emocional" em relação ao PEE. Depois de relatar os encontros que teve com Darcy Ribeiro, que deram origem ao seu criticismo em relação aos CIEPs, reconhece que sua reação reflete preconceitos e vícios da academia: tendência a trabalhar o tempo todo com a complexidade, a desconfiar dos políticos e a "não sujar as mãos". Afirma que o impacto nacional causado pelo programa dos CIEPs colocou em discussão não as escolas, mas a disputa político-partidária representada por Brizola, Darcy e Niemeyer.

A autora, a despeito de reconhecer o boicote da imprensa ao Governo Brizola, considera que as críticas veiculadas expressam a polêmica levantada pelos CIEPs: falta de participação dos profissionais de educação no Programa; constituição de uma rede paralela; escola como outdoor; prioridade ao tempo integral, em detrimento da existência do terceiro turno; incerteza sobre os benefícios do horário integral; ausência de proposta pedagógica; despreparo na formação de professores; custo muito alto. Brandão conclui que o CIEP representou ousadia para romper com a tradição, apesar das mazelas enfrentadas por causa da urgência da implantação. Considera que o Programa deixou questões para reflexão, como a discussão a respeito das crianças que completam a renda familiar; se espaço físico ampliado com tantas atividades complementares atende à demanda das camadas populares; se o tempo mal usado não reforçará o estigma desenvolvido pelos próprios idealizadores dos CIEPs. Destacou como positivo que prédio e horário novos trazem motivação, planos e idéias novas; que o projeto de horário integral criou condições para treinamento em serviço e a figura das professoras-orientadoras; e que foi boa a proposta do ensino da língua como eixo interdisciplinar.

Entre as críticas, era lugar comum abordar o populismo, introduzido por Vanilda Paiva (1985) no debate com Darcy Ribeiro (1985) através de jornais. Os argumentos, retomados por Mignot (1988), focalizavam ausência de transparência em relação a custos, critério de localização, número de escolas concluídas e de alunos atendidos. Lobo Jr. (1986) considerou que o populismo devia-se ao fato de o projeto dos CIEPs partilhar da concepção escolanovista que se filiava ao pensamento liberal.

A tese de Leal (1991) sistematizou a literatura sobre clientelismo, definindo-o como a distribuição de benefícios oriundos de recursos públicos efetivada por indivíduos ou grupos no poder, para atender interesses particulares em troca de lealdade, apoio político e até vantagens econômicas, resultando em alto grau de ineficiência social. $\mathrm{O}$ estudo mapeou as práticas clientelistas na educação de $1^{\circ}$ e $2^{\circ}$ graus no Brasil. Procurou demonstrar que a fragmentação de decisões da política educacional para o ensino básico a torna predominantemente clientelista em situações como aquisição e distribuição de livros didáticos, merenda e bolsas de estudo; construção de escolas; recrutamento e lotação de professores. A questão da construção dos CIEPs mereceu destaque porque revelou a contradição entre o planejamento do PEE e seu resultado. O diagnóstico que deu origem ao Programa, além de abrir certo espaço à participação do professor, foi coerente com o problema educacional quando criticou o funcionamento e a estrutura da escola pública e enfatizou a necessidade de se repensarem aspectos do ensino-aprendizagem. Entretanto, a implantação afastou-se do diagnóstico na medida em que se concentrou na construção dos CIEPs.

$\mathrm{O}$ fato dos CIEPs cumprirem uma função social no que se refere ao atendimento à demanda por escola pública em áreas carentes, não eliminou a faceta clientelista do pro- 
jeto, revelada pelo critério de escolha das áreas a serem construídas, pelo excessivo número de CIEPs inaugurados em período pré-eleitoral e pela contratação de pessoal sem concurso. (Leal, 1991, p. 150)

Cunha (1991) considerou que a localização inadequada dos "escolões" não eliminou o terceiro turno, que a pressa nas construções para fins eleitorais deixou vazamentos e afundamentos, e que obras monumentais como o CIEP, além de absorverem grandes recursos financeiros, têm o objetivo de aumentar os valores simbólicos dos governantes e engordar as "caixinhas".

O segundo tema das críticas, a inviabilidade de universalização da escola de horário integral, foi primeiramente abordado por Paro et al. (1988b, 1988c) como resultado de estudo promovido pela Fundação Carlos Chagas, alegando, da mesma forma que Brandão (1989), que a simples extensão da escolaridade diária não garantia o funcionamento ótimo da escola. É certo que um dos graves problemas da educação é o pequeno tempo de permanência do aluno na escola, mas há outros tão graves quanto este, como por exemplo: a superlotação das salas de aula, que redunda em evasão e repetência e que pode ser solucionado independentemente da extensão da escolaridade; o salário do professor, que perde motivação, não se aperfeiçoa e tem que trabalhar em vários lugares; a precariedade de instalações; a escassez de material didático etc. Os autores consideraram que as propostas de horário integral ignoravam que o ponto de partida daquele momento não eram quatro horas diárias; de fato, esse mínimo estabelecido por lei, oferecido em condições adequadas para o bom aproveitamento do ensino, ainda estava para ser atingido. Assim, o custo muito alto com incerteza de benefício inviabilizava a universalização da escola de horário integral no Ensino Fundamental. Kramer (1991) acrescentou que, diante do alto custo, a escola de horário integral só se justificaria dentro de uma política global.

Oliveira (1991) distinguiu dois tipos de críticas ao custo dos CIEPs: de um lado, os que discordavam da oportunidade de implantar uma escola como essa; de outro, as que incidiam sobre a análise dos gastos dessa implantação. Rebate a impossibilidade de universalização do atendimento em tempo integral quando não se garantia ainda ensino de boa qualidade em tempo parcial, alegando que a escola unitária tem sido confundida com uniformidade de atendimento. No mesmo sentido, Coelho (1996) afirmou que qualidade emancipatória a ser desenvolvida no ensino público fundamental requer democracia que se lê, minimamente, como acesso e permanência na escola, mesmo que seja necessário facultar condições desiguais para que as crianças das classes desprivilegiadas possam se tornar iguais. Concluiu que a extensão da quantidade de horas na escola é condição para desenvolver a qualidade emancipatória, inserindo conteúdo político na qualidade de ensino.

Um artigo específico sobre o tema (Costa, 1991) comparou os custos de uma escola convencional e de um CIEP de $1^{\mathrm{a}}$ a $4^{\mathrm{a}}$ série, assim como os custos de outro par de $5^{\mathrm{a}}$ a $8^{\mathrm{a}}$ série. A autora dividiu os custos em pessoal, material e capital (prédio). Exemplificando com os dados do primeiro segmento, o CIEP apresentou custo aluno/ano três vezes maior que o da escola convencional nos aspectos pessoal e material, e duas vezes maior no tocante ao prédio. Concluiu que as despesas assistenciais não eram relevantes. Como tanto no CIEP quanto na outra escola a maior parte do custo aluno (60\%) estava na despesa com pessoal, este se mostrou realmente o fator significativo. $\mathrm{Ou}$ seja, o CIEP com sua capacidade completa apresentaria resultado diferente, pois a comparação foi feita entre taxas, e não entre valores absolutos. Para a autora, a educação devia ser vista como investimento, e não como despesa.

A terceira vertente da crítica, que discutiu a função da escola, também foi introduzida por texto decorrente do estudo proposto pela Fundação Carlos Chagas. Paro et al. (1988a), ao responderem se essa escola poderia servir de instrumento para a universalização da educação elementar às amplas camadas da população, reafirmaram a função de instrução da escola, sem desconhecer a de socialização, mais importante para as crianças das camadas populares que não 
contam com alternativas de lazer em ambientes coletivos diversificados. Entretanto, consideraram que na escola real a instrução tem sido reduzida a mínimos insignificantes e a socialização tem se consistido de práticas autoritárias que recalcam a cultura do dominado, até que essas crianças sejam expulsas da escola sem aprender o mínimo necessário. O que se divisava por trás do caráter formador da escola voltada para as classes trabalhadoras era a concepção de pobreza como problema moral, que devia ser eliminado através da educação integral. Argumentaram que as propostas de horário integral no Brasil daquele momento se apresentavam como alternativas a instituições como a Fundação Estadual do Bem-Estar do Menor (FEBEM), que, se obtiveram êxito na segregação da ameaça que as crianças das classes populares representam, fracassaram inteiramente na sua "ressocialização". Mignot (1988) concluiu, da sua observação, que o papel da escola era suprir carências. Como resultado, deixava de cumprir sua função de ensinar, agravando a carência dos pobres.

Arroyo (1988), ao discorrer sobre as funções que as escolas de tempo integral assumiram ao longo da história, destacou seu caráter de instituição total, em que se valorizava mais a socialização do que a instrução. Alertou para a percepção negativa da pobreza que estas instituições, destinadas a salvar os filhos dos trabalhadores pobres, têm, mostrando quão violenta pode ser a relação pedagógica. Ao responder à pergunta "que sentido pode ter, para as camadas populares, a defesa da escola pública de horário integral?", indicou que ela poderia servir como instrumento de fortalecimento político cultural dos trabalhadores, na medida em que contribui para a constituição de um sistema de ensino mais definido, com um corpo profissional mais consistente, trabalhando em tempo integral nessa escola, conformando-se num interlocutor para a classe trabalhadora; finalmente, reconheceu que, apesar dos limites das relações pedagógicas, a força educativa da escola reside em permitir uma experiência humana e social menos controlada que a fábrica. Cavalieri (1996) considera que há, atualmente, ampliação das funções da escola por modificação da natureza da instrução escolar. Assim, o tempo de permanência diária passou a condição para que a escola possa desempenhar essas novas atribuições.

A comparação feita por Leonardos em três pesquisas (1990, 1991b e 1992), entre um CIEP e uma escola convencional situados na mesma comunidade, Cidade de Deus, ambos de $1^{\mathrm{a}}$ a $4^{\mathrm{a}}$ série, trouxe informações novas para a discussão sobre a função da escola de horário integral. O estudo, que considerou pensamento crítico como capacidade de avaliar uma idéia, tomar uma posição e argumentar coerentemente pró ou contra a mesma, investigou a fala, a leitura e a escrita em turmas de $4^{\mathrm{a}}$ série. Apesar de pertencerem à mesma comunidade, o levantamento socioeconômico indicou que os alunos do CIEP eram mais pobres, em sua maioria oriundos de famílias desestruturadas, ainda que apresentassem histórico escolar - número de séries já repetidas - semelhante. Os resultados apontaram que os alunos do CIEP possuíam desempenho qualitativamente distinto dos alunos da escola convencional, na medida em que revelavam domínio superior significativo na habilidade da fala e desempenho homogêneo nas habilidades da fala, da leitura e da escrita, embora fosse baixo, pois nenhum índice ultrapassou $65,6 \%$. Os da escola tradicional de meio período mostraram grande oscilação nas três habilidades, com índice pouco maior, porém não significativo, na habilidade escrita, que o do CIEP. A análise da freqüência dos temas escolhidos pelos alunos das duas escolas foi significativa, sugerindo que existiam diferenças entre eles que transcendiam a capacidade de avaliação e argumentação, ficando mais no campo ideológico.

Na pesquisa realizada em 1992, desdobrando a anterior que analisara a capacidade crítica apenas pelo aspecto cognitivo, Leonardos estuda as redações argumentativas dos alunos que foram submetidas à análise de conteúdo, confirmando a antecipação segundo a qual os alunos do CIEP apresentariam uma maior capacidade de pensamento crítico em sua dimensão ideológica. O estudo concluiu que entre os alunos do CIEP a postura foi considerada não-repetidora do senso comum, pois havia tentativa de elaboração 
própria; em compensação, o discurso dos alunos da escola convencional de meio período enquadrava-se mais na repetição da palavra autorizada. Não há como negar o impacto dos programas educacionais - progressista ou tradicional - na diferença verificada, apesar de não se poder afirmar que este fosse o único fator determinante. Os alunos da escola convencional se reconheciam como classe média "de fora" da Cidade de Deus, ou elite da classe baixa. No CIEP, ao contrário, manifesta-se uma postura de assumir sua pertinência a todos os espaços daquela comunidade.

\section{[...] enquanto grupo social, os alunos do CIEP se iden-}

tificam com a classe baixa, estabelecem relação de pertinência com a sua comunidade, reivindicam uma postura menos discriminatória por parte dos "lá de fora" e questionam o discurso dominante no que concerne a associações do tipo pobreza-violência. (Leonardos, 1992, p. 33)

A implantação do programa questionou a pertinência do horário integral, tendo em vista a necessidade de a criança colaborar com a renda familiar (Paro et al., 1988a; Cunha, 1991; Kramer, 1991). Perissé (1994), analisando a evasão de alunos de um CIEP, concluiu que, diferentemente do que se supunha, o motivo principal para o abandono do horário integral não era a necessidade de complementar a renda familiar, mas a não implementação da proposta original, tanto por responsabilidade do governo da época quanto pela dos profissionais que trabalhavam naquele CIEP, deixando os alunos na ociosidade por longo período do dia. Outra crítica à implantação foi a contradição observada entre o discurso da equipe central do PEE e a prática das escolas (Lima, 1988), ou entre o discurso e a prática dos próprios professores (Aguiar, 1991). Oliveira (1991) atribuiu ao discurso salvacionista de Brizola, que justificava o programa, a origem do estigma do CIEP como escola para pobre.

Três aspectos positivos mereceram destaque por terem sido citados, em contextos diversos, tanto por críticos como por defensores da implantação da escola de horário integral. O primeiro e mais significativo para a permanência da demanda por essa escola é a satisfação dos pais. Paro et al.(1988a) reconheceram que, à primeira vista, a população desejava esses projetos que estavam sendo oferecidos. Lobo Jr. (1988) atribuiu o entusiasmo das comunidades e das equipes internas em torno do CIEP a uma estreita ligação entre a proposta populista do CIEP e um certo consenso vulgar do que seja escola de qualidade. Lima (1988) registrou que, apesar da omissão da escola em discutir a disciplina, diante de tantos casos de violência, a visão dos pais era positiva, um descanso saber que os filhos estavam na escola. Leonardos (1991a) compartilhou esta percepção ao afirmar que o conceito de CIEP da comunidade em geral era de um prédio em que funcionava uma escola de horário integral, o que lhes dava tranquilidade para trabalhar e mantinha as crianças alimentadas. Oliveira (1991) mencionou a expectativa favorável da população, que foi confirmada em avaliação externa realizada em 1994 (Maurício \& Silva, 1995), segundo a qual o índice de aprovação da comunidade em relação ao horário integral, ao prédio escolar, à integração criançaescola e à qualidade de vida da comunidade após a implantação da escola ficou acima de $80 \%$.

O segundo aspecto positivo enfocou o horário integral do professor, que, segundo Paro et al.(1988b) e Brandão (1989), permitia intervalos para planejamento, preparação de material didático e aperfeiçoamento profissional, indispensável diante do baixo padrão de qualidade do professor, resultante do desprestígio da profissão e dos baixos salários. Arroyo (1988) e Costa (1995) abordaram outro aspecto, considerando que o horário mais extenso do professor contribui para maior envolvimento e constituição de um sistema de ensino mais definido, com um corpo profissional mais consistente, conformando-se num interlocutor para a classe trabalhadora.

O último aspecto compartilhado por vários autores citados foi o de que a proposta dos CIEPs suscitou discussão sobre a escola pública. O debate contribuiu para o avanço do processo de democratização da escola pública, tanto que nas campanhas eleitorais, apesar de ressalvas, figurou como plataforma política dos candidatos (Mignot, 1988). Brandão 
(1989) destacou que, apesar das críticas que o CIEP sofreu, figurou como plataforma política de todos os candidatos ao governo do estado; tornou-se "nome próprio" para escola de tempo integral; entrou na vida dos usuários, nos debates de educação, dos intelectuais e dos políticos. Para Oliveira (1991), a discussão sobre a inadequação da escola pública decorrente da introdução do projeto teve como conseqüência a incorporação do direito à educação de boa qualidade, em jornada ampliada, às reivindicações das classes trabalhadoras na Constituição do Estado e na Lei Orgânica do Município do Rio de Janeiro. Garcia (1992) resume tudo dizendo que o CIEP colocou a discussão sobre escola na rua.

\section{Representações sociais de quem convive com a escola pública de horário integral}

A pesquisa de campo foi desenvolvida com a finalidade de identificar a representação social que professores, funcionários, alunos e seus pais tinham da escola de horário integral que freqüentavam. Através da representação social seria possível dimensionar a demanda subjetiva potencial por esta escola. A representação social constitui uma forma de conhecimento, um saber prático que se refere exatamente à experiência a partir da qual ele se produz, e que serve para agir sobre o mundo (Jodelet, 1989). Pela relação que estabelece com o imaginário social e por levar à ação, a representação social torna-se essencial para compreender mecanismos que interferem no processo educativo, pois as interações sociais vão criando consensos que constituem verdadeiras "teorias" do senso comum (Alves-Mazzotti, 1994). As representações sociais são estudadas, de um lado, como algo constituído. Para caracterizá-las, procurou-se observar: a atitude em relação ao objeto, as informações sobre o objeto e o campo de representação do objeto. De outro lado, estudam-se os processos formadores da representação social, que foram chamados por Moscovici de objetivação e de ancoragem (idem).

A objetivação é a transformação de um conceito em uma imagem concreta através de um processo de- terminado por condicionantes culturais e por valores, gerando uma imagem coerente e de fácil expressão do objeto da representação social, como, no caso, a de Brizolão. A naturalização dessa imagem, ou núcleo figurativo, confere tal estabilidade e materialidade à representação social que ela adquire o estatuto de referente capaz de orientar percepções e julgamentos. Para modificar uma representação é necessário atingir seu núcleo figurativo, pois dele depende o significado da representação. A ancoragem trata do enraizamento social da representação, sua inserção no pensamento preexistente. Para Jodelet (1989), a intervenção do social no processo de ancoragem se dá na significação e na utilidade que confere à representação social. A ancoragem desempenha a função de criar familiaridade com o que é estranho, ameaçador. Nesse processo, podem prevalecer posições preestabelecidas, através de mecanismos de classificação, categorização e rotulação, típicos da ancoragem, revelando algo da "teoria" que se tem a respeito do objeto.

A pesquisa se desenvolveu em quatro escolas de horário integral do primeiro segmento do ensino fundamental no Rio de Janeiro, duas sob administração municipal e duas, estadual. Para a seleção das escolas foram seguidas diretrizes comuns: as quatro eram CIEPs, com marca de horário integral impressa nos prédios; foram priorizados indicadores de bom desempenho; as escolas estavam localizadas em áreas populares de periferia, com grande densidade urbana. No total, foram feitas 30 visitas às escolas e aplicados questionários a 568 respondentes (312 alunos, 60 pais, 142 professores e 54 funcionários), entre agosto e dezembro de 2000.

Entrevistas, gravadas ou anotadas, realizadas por ocasião da matrícula (entre dezembro de 1998 e fevereiro de 1999), foram a fonte para a formulação do questionário e modelo para a coleta de associação de idéias. Foram colhidos 44 depoimentos de pais de alunos de escola de horário integral, de quatro professores e de seis diretores, em seis escolas visitadas. Estes instrumentos foram testados com os professores que frequientam o Fórum Permanente de Debates 
“Tempo Integral, Educação Integral". Este fórum, promovido pelo Núcleo de Estudos da Escola Pública de Horário Integral (NEEPHI), da UniRio, é constituído por público privilegiado, pois são profissionais que buscam discutir a escola pública de horário integral sem qualquer pressão institucional.

Para identificar os elementos constitutivos do núcleo central da representação social de escola de horário integral, foi pedido aos professores do III Fórum que fizessem uma associação livre de idéias a respeito de cinco temas: escola pública; escola pública de horário integral; CIEP; Brizolão; escola para pobre. A partir daí foi composto um repertório semântico de 80 noções, através do levantamento de freqüência dos termos empregados e da aglutinação de significações semelhantes. Esse conjunto foi apresentado no VII Fórum para que os professores fizessem uma hierarquização semântica, priorizando cinco atributos para cada tema. Tabulado o resultado, foram feitos dois conjuntos idênticos de dezessete afirmativas para que alunos, pais, professores e funcionários, nas escolas pesquisadas, atribuíssem falso ou verdadeiro a no máximo cinco afirmativas tendo em vista a concepção de escola de horário integral ideal e cinco para a escola de horário integral que conheciam. O confronto entre ideal/real e falso/verdadeiro permitiu configurar as representações sociais construídas. Seus traços ganharam nitidez ao serem expostos aos resultados da tabulação dos questionários (sim/não) a respeito dos motivos que levam à procura ou abandono da escola pública de horário integral.

Para consolidar os dados, foram acolhidas as respostas com índices superiores a 70\% em pelo menos três escolas, na parte relativa à motivação para estudar. Os atributos relativos à concepção de escola ideal $x$ real foram contemplados com índices de $50 \%$ ou mais, também em três escolas. Eventualmente, quando se percebia que alguma categoria tornava-se significativa para um dos grupos de inserção na escola por outros indicadores, os critérios eram alargados.

O que ressaltou no confronto de pontos de vista foi o enfoque oposto de pais e alunos, de um lado, e professores e funcionários, de outro. Se considerarmos que as respostas dadas à motivação para a demanda pela escola de horário integral podem ser categorizadas pelos verbos preferir - que implica comparação -, gostar, convir - que implicam praticidade -, e precisar - uma gradação da opção à falta de opção -, veremos que pais e alunos, que usufruem dos serviços da escola, procuram o horário integral por preferir e gostar, prioritariamente no caso dos pais e exclusivamente no caso dos alunos. O que eles preferem estudar mais - é que a escola cumpra a sua função com qualidade - bons professores - e que eles gostem - mãe e aluno - do serviço prestado. Os pais não desconhecem a necessidade - não deixar a criança na rua e precisar trabalhar -, mas colocam-na num patamar inferior. As crianças ainda não se preocupam com a necessidade. Reforçando a interpretação de que é o gostar que leva ao horário integral, os fatores relacionados como não-significativos para a demanda do horário integral excluíram esse verbo. Os aspectos de conveniência - "ficar sem criança" e "irmão estudar nesta escola" - e de falta de opção - "só há vaga ấ" foram considerados sem relevância para a demanda por esta escola.

Tanto alunos como pais não elegeram qualquer razão para abandonar o horário integral. Ao relacionarem os motivos que não levam ao abandono do turno único, colocaram, em visão comum, logo no primeiro plano, o fato de ser escola para pobre, ou seja, esse atributo não diminui ou muda a função da escola, que continua sendo vista como desejável; num segundo plano, pais e alunos apontaram que a necessidade - "precisar trabalhar" ou "ajudar em casa" - não é suficiente para fazê-los abandonar a escola. Ambos reconheceram que criança tem que estudar, que o fato de não gostar não leva ao afastamento da escola. Os alunos ainda vão mais longe, afirmando que mesmo se a escola tiver aspectos negativos - excesso de reprovação, falta de professor ou dificuldade na relação professor/aluno - eles não são pretexto para a saída da escola de horário integral. Em síntese, o discurso dos pais e dos alunos, além de gostar e preferir, dei- 
xou claro o reconhecimento da função e da necessidade da escola, e, implicitamente, que há diferentes padrões de qualidade entre as escolas.

Professores e funcionários, com ponto de vista do servidor, comum aos dois, construíram um discurso, em primeiro plano, de necessidade - "criança não ficar na rua" e "mãe precisar trabalhar" - e num segundo plano de conveniência - "irmão já estuda aî" e "escola é mais próxima". A necessidade que leva ao horário integral também afasta desta escola, fatores apontados com ênfase pelos professores - "aluno precisa trabalhar" ou "ajudar em casa" - e secundariamente pelos funcionários, diferente dos pais e alunos, que não encontraram qualquer situação de necessidade ou mesmo de conveniência que justificasse o abandono da escola. Os funcionários partilharam com os alunos a idéia de que brincar não é função da escola, assim, não leva ao horário integral, mas ficar sem brincar também não tira desta escola. Também tiveram em comum com pais e alunos a idéia de que escola para pobre não deixa de ser escola.

Destaca-se, do ponto de vista de professores e funcionários, que na ótica deles a escola de horário integral só se justifica como necessidade e conveniência. O fato de não reconhecerem o gostar e o preferir como motivação para esta escola desqualifica o usuário, como se ele fosse objeto exclusivo de necessidade, portanto, desprovido de atributos que caracterizam o ser humano. Indiretamente, desqualificam o próprio trabalho, porque, se atendem apenas a necessidade, não podem ter reconhecimento de qualidade, não podem ser preferidos, queixa tão presente no discurso dos professores: "eles não reconhecem nosso trabalho", "não vêm à reunião de pais" etc.

Sintetizando, a representação dos professores, corporificada na palavra Brizolão, tem no seu núcleo a idéia de escola para pobre e depósito de criança, e está associada à noção de descaso, assistencialismo e qualidade ruim. A representação social dos pais, partilhada pelos alunos, está centrada na satisfação/prazer, sem desprezar a necessidade; tem como núcleo a idéia de lazer que se relaciona com futuro e educa- ção; a função da escola - estudar - e seu instrumento - bom professor - estão contemplados.

\section{Demanda pela escola pública de horário integral: necessidade $x$ satisfação}

Nem todas as questões levantadas pela literatura foram iluminadas pelas representações colhidas no campo. No entanto, as diferentes óticas sobre a função social da escola de horário integral e sobre os fatores que mobilizam para a demanda dessa escola, por parte dos pais e dos professores, trouxeram contribuição relevante para a discussão dessa escola, que, segundo a lei $\mathrm{n}^{\circ}$ 9.394/95, é meta a ser alcançada.

O discurso salvacionista de Leonel Brizola a respeito do CIEP, que passou a ser conhecido como Brizolão, suscitou a idéia de escola de marginal. Nas quatro escolas estudadas, o estigma de escola para pobre não foi considerado fator de rejeição por pais, alunos e funcionários. Não se fez associação entre concepção de educação integral e a noção da pobreza como problema social a ser eliminado por esta escola, função levantada na literatura para instituições totais. Assim, o CIEP não desempenhou o papel de salvaguardar a sociedade da pobreza. Mas também não ficou reconhecida a função de ser uma escola para salvar as crianças carentes da marginalidade. Concluiu-se que, ou esta escola não é considerada de pobre, ou o fato de ser assim considerada não interfere na demanda por ela. A totalidade dos pais pesquisados e a média de $90 \%$ de alunos e funcionários das quatro escolas responderam que ser uma escola para pobre não conduz ao abandono do horário integral.

A associação entre depósito de criança e Brizolão foi feita exclusivamente por professores nas várias escolas e também no fórum do NEEPHI. Pelo ponto de vista dos alunos, Brizolão adquiriu um significado bastante diferente. A concepção de escola que construíram foi que ela devia ser organizada, em primeiro plano, e ter lazer, em segundo. Ao analisarem as escolas que freqüentam tendo por base essa concepção, os alunos das quatro escolas disseram que ela promo- 
via educação, em primeiro plano, e que tinha lazer, em segundo. Está descrita a escola deles, mas eles dão nome a ela: num mesmo patamar, dizem que é Brizolão e que é CIEP. Assim, para os alunos, não há distinção entre CIEP e Brizolão; além disso, ambos estão associados a lazer.

Fez-se notar a diferença entre escola para pobre, que a princípio não suscita rejeição ou constrangimento e escola pobre, relegada, descuidada, suja, bagunçada, pichada, que é até freqüentada por marginal. Essa é a escola rejeitada, que na associação de idéias feita pelos professores do fórum do NEEPHI é a escola da carência, da comida, do descaso, do descrédito, da discriminação, do desrespeito, da desvalorização, do estigma, do fracasso, do paternalismo, da qualidade ruim. Essa escola os professores chamam de Brizolão, mas também reconhecem esses atributos na escola pública comum. Os pais percebem diferentes graus de qualidade nas escolas, mas não denominam, como os professores, as consideradas ruins de Brizolão ou escola para pobre. Os quatro grupos pesquisados afirmaram, com índices altos, que a escola que vivenciam não é uma bagunça. As mães se informam, observam, tomam conta. Os alunos não estão lá por acaso.

O segundo aspecto significativo para a demanda pela escola de horário integral é a satisfação dos pais, mencionada por vários autores citados. Essa avaliação positiva que os pais têm da função social desempenhada pela escola pública de horário integral confirmou-se. Os pais concebem a escola como uma instituição que prepara o futuro, e para isso deve ter lazer e ser organizada. Avaliam que a escola freqüentada pelo filho preenche essa função, tornando-a uma necessidade, ainda que ofereça lazer em patamar aquém do desejável (satisfação); afirmam com convicção que essa escola não é uma bagunça e acrescentam que, além de suas expectativas, ela tem participação. A visão dos pais é construída a partir de vários fatores, entre os quais a satisfação dos filhos. As crianças tinham expectativa de que a escola tivesse lazer, e os pais registram que essa expectativa é atendida.
Os argumentos usados pelos pais para explicar por que seus filhos estudam nessa escola priorizaram o gostar em detrimento da necessidade (satisfação, prazer). Quando destacam, em primeiro plano, a avaliação subjetiva - a mãe e o aluno gostam -, os pais atribuem a si o papel de sujeitos, com direito a opção, e não meros objetos da necessidade; também reconhecem nos filhos, apesar de serem crianças, o papel de sujeitos com capacidade de avaliação e de escolha; o terceiro argumento - os professores são bons -, além de continuar centrado no reconhecimento que têm da capacidade de avaliar, outorga a eles o julgamento do que simboliza, por excelência, a qualidade da escola: o desempenho do professor. Só num segundo patamar os pais vão preocupar-se com os aspectos materiais: destacam a segurança da criança, seu bem-estar físico, deixando evidenciar sua responsabilidade enquanto pais; essa responsabilidade permanece quando enfocam a finalidade da escola - estudar mais - mesmo antes de chegar ao último argumento: a criança vai para a escola de horário integral porque a mãe precisa trabalhar. Finalmente, a satisfação dos pais também é contemplada quando não conseguem consolidar qualquer argumento que justifique a saída da escola de horário integral, nem mesmo a necessidade. Perguntados diretamente se tirariam seus filhos dessa escola, a resposta negativa ficou num patamar de $90 \%$ nas escolas estaduais e $70 \%$ nas escolas municipais.

Uma terceira temática, que mantém uma certa relação com a anterior, foi tangenciada por alguns autores. A dissertação de Lima (1988) apontou o abismo entre o que a equipe central pensava da carência da criança popular e a carência real, e a incapacidade da equipe da escola em propor adaptações à proposta do PEE para atender a essa criança, redundando em contradição entre o discurso e a prática dos professores. O entendimento oposto do professor (e, por extensão, do funcionário) de necessidade/carência, e o do pai (e, por extensão, do aluno) de satisfação/prazer a respeito de por que o aluno estuda em horário integral ou por que o abandona, mostra que professor e pai têm compreensão conflitante de como vive, como se comporta, o que pensa o segmento social do qual 
o aluno faz parte. As visões detectadas no decorrer desta pesquisa levaram a supor que o abismo não está entre os formuladores da proposta de horário integral e os beneficiários dela. $\mathrm{O}$ abismo parece estar entre os formuladores (equipe central) e os executores (professores) na escola, de um lado, e os beneficiários (pais e alunos) de outro. Ou seja, formuladores, professores e, inclusive, analistas da escola de horário integral têm visão comum a respeito das necessidades do aluno que busca esta escola, em oposição àquela dos pais.

Os professores das quatro escolas e os que foram pesquisados durante os Fóruns Permanentes de Debates "Tempo Integral, Educação Integral" promovido pelo NEEPHI só reconhecem no aluno necessidade, carência, falta. O aluno vai para a escola de horário integral porque a mãe trabalha, porque ela não tem alternativa; assim, a escola é reduzida à última hipótese, à falta de opção. Num segundo patamar, o aluno vai para a escola de horário integral para não ficar na rua, exposto a todos os males que podem transformálo num marginal. Esta concepção implica o reconhecimento da escola como um depósito, onde a criança fica guardada enquanto a mãe vai trabalhar, para suprir a carência de necessidades objetivas e primárias. Assim, o professor, de um lado, afirma que a escola não deve ser um depósito de crianças, que chama de Brizolão, de outro atribui a ela a função de depósito de crianças. Além disso, dos quatro grupos, o professor foi o único a afirmar que o aluno abandona a escola porque precisa trabalhar ou porque precisa ajudar em casa para os pais poderem trabalhar, indicando mais uma vez o aluno como objeto da determinação da necessidade/carência.

Entretanto, essa não é a visão dos pais. Como já foi explicitado anteriormente, os pais priorizam a escolha, eles preferem ou gostam, mostram que os motivos que os levam a colocar seus filhos na escola de horário integral é a opção fruto de uma avaliação feita por alguém capaz disso, um sujeito, e não um objeto de carências. Os pais, quando não consolidam qualquer motivo para o abandono da escola de horário integral, desfazem a compreensão da falta de pertinên- cia do horário integral escolar tendo em vista a necessidade da criança colaborar com a renda familiar (Paro et al., 1988a; Cunha, 1991; Mignot, 1988; Kramer, 1991) e corroboram os resultados da pesquisa de Perissé (1994): a evasão ocorre pelo não cumprimento da proposta para a escola de horário integral.

E por que temos essa leitura tão destoante daquela dos pais de nossos alunos? Alguns autores citados deram pistas a respeito. Leonardos (1991b) afirmou que a manutenção das características básicas deste programa estaria ameaçada num momento de falta de apoio político e financeiro, pois a proposta do CIEP fora feita para a comunidade, e não com a comunidade do aluno de baixa renda. Esta percepção tem por base a mesma compreensão de que a comunidade não é capaz de projetar para si mesma uma escola dessa qualidade. Passados dez anos, o projeto só se sustentou em escolas onde a liderança do diretor e a coesão da equipe foram capazes de estabelecer vínculos com a comunidade ou com a administração que permitissem a continuidade, não do projeto como um todo, mas do horário integral. Outro estudo (Guimarães, 1992) indicou que os professores não conseguiam incorporar à sua prática procedimentos mais coerentes com uma visão transformadora, por causa de preconceito de classe e de desconhecimento das causas sociais do fracasso escolar.

A relação entre classe social e diferentes interpretações das funções a serem desempenhadas pela escola já havia sido apontada por alguns autores. Coelho (1996) afirmava que a qualidade emancipatória a ser desenvolvida no ensino público fundamental seria fruto da produção de conhecimentos resultante do conflito de diferentes culturas (a do aluno e a do professor) e que o tempo de permanência do professor no ambiente escolar era indispensável para que esse processo pudesse deslanchar.

Sintetizando, a pesquisa realizada nestas quatro escolas situadas em regiões carentes levou ao reconhecimento de duas representações sociais diversas, e mesmo antagônicas, da escola pública de horário integral. A primeira, centrada na necessidade/carência do aluno para justificar a existência desta escola, 
é partilhada por professores, tanto das escolas quanto do Fórum, e coincide com a análise de autores que escreveram a respeito dos CIEPs. Esta representação, corporificada na palavra Brizolão, tem no seu núcleo a idéia de escola para pobre e depósito de crianças, e está associada à noção de descaso, assistencialismo e má qualidade. A representação dos pais, partilhada pelos alunos, está centrada na satisfação/prazer, sem desprezar a necessidade. Tem como núcleo a idéia de lazer que se relaciona com futuro e educação. A função da escola - estudar - e seu instrumento - bom professor - estão contemplados.

A constatação dessas representações diferentes a respeito da escola, da expectativa que se tem dela e, portanto, das atribuições que deve atender, naturalmente fruto de culturas diferentes, oriundas, entre outros fatores, de posicionamentos de classe diferenciados, traz à discussão dois temas inter-relacionados: a integração da escola à comunidade e o reconhecimento de que existe uma cultura local que é condição para o desenvolvimento do processo de educação. Assim, para a aproximação entre as duas concepções de função de escola delineadas neste trabalho - a de local de convivência e a de utilidade econômico-social faz-se necessário desenvolver a interação entre escola e comunidade, instâncias de participação e decisão dos pais, e todos os espaços cotidianos que favoreçam a inclusão da expectativa dos pais no projeto pedagógico da escola.

LÚCIA VELLOSO MAURÍCIO, doutora em educação pela Faculdade de Educação da Universidade Federal do Rio de Janeiro, é professora adjunta do mestrado em educação da Universidade Estácio de Sá, professora adjunta da Faculdade de Formação de Professores da Universidade do Estado do Rio de Janeiro e consultora da Fundação Darcy Ribeiro. Publicou recentemente: Darcy Ribeiro. In: FÁVERO, M. L., BRITTO, J. (orgs.). Dicionário de educadores no Brasil: da Colônia aos dias atuais (Rio de Janeiro: Editora UFRJ/MEC/INEP, 1999, p. 140-147); Permanência do horário integral nas escolas públicas do Rio de Janeiro: no campo e na produção escrita. In: COELHO, L. M., CAVALIERE, A. M. (orgs.). Educação brasileira e(m) tempo integral. (Petrópolis: Vozes, 2002, p. 112-132).E-mail: luciavelloso@terra.com.br

\section{Referências bibliográficas}

AGUIAR, Maria de Fátima, (1991). Inovações metodológicas: seus caminhos e descaminhos. Dissertação de mestrado. Faculdade de Educação da Universidade do Estado do Rio de Janeiro.

ALVES-MAZZOTTI, Alda Judith, (1994). Representações sociais: aspectos teóricos e aplicações à educação. Em Aberto, v. 14, $\mathrm{n}^{\circ} 61$, p. 60-78.

ARROYO, Miguel Gonzales, (1988). O direito ao tempo de escola. Cadernos de Pesquisa, $\mathrm{n}^{\circ}$ 65, p. 3-10.

BRANDÃO, Zaia, (1989). A escola de $1^{\circ}$ grau em tempo integral: as lições da prática. Educação e Sociedade, n 32, p. 116-129.

CAVALIERI, Ana Maria, (1996). A escola de educação integral: em direção a uma educação escolar multidimensional. Tese de doutorado. Faculdade de Educação da Universidade Federal do Rio de Janeiro.

(s/d.). O currículo dos CIEPs. Rio de Janeiro: (digitado).

COELHO, Ligia Martha C. Costa, (1996). Escola pública de horário integral e qualidade de ensino. Ensaio, v. 11, nº 4, p. 121-128.

COSTA, Marly Abreu, (1991). Comparação das estimativas do custo/aluno em dois CIEPs e duas escolas convencionais no Município do Rio de Janeiro. Educação e Sociedade, n 40 , p. $486-501$.

(1995). Qualidade de ensino: a escola pública de tempo integral em questão. Tese de doutorado. Faculdade de Educação da Universidade Federal do Rio de Janeiro.

CUNHA, Luiz Antônio, (1991). Estado, educação e democracia no Brasil. $2^{\mathrm{a}}$ ed. São Paulo: Cortez / EDUFF / FLACSO.

ESTADO DO RIO DE JANEIRO, (1983). Escola Viva: viva a escola 1 e 2. Rio de Janeiro: Comissão Coordenadora de Educação e Cultura.

, (1983). Plano de Desenvolvimento Econômico e Social do Estado do Rio de Janeiro 1984/1987. Lei RJ 705, de 21 de dezembro.

(1985). Falas ao professor. Rio de Janeiro: Comissão Coordenadora de Educação e Cultura.

GARCIA, Regina, (1992). CIEP: a paixão deslocada. Proposta n. 52. Rio de Janeiro: FASE. p. 11-13.

GUIMARÃES, Miriam Reis, (1992). A escola de horário integral: um projeto de escola crítica em construção. Dissertação de mestrado. Faculdade de Educação da Universidade do Estado do Rio de Janeiro. 
JODELET, Denise, (1989). Représentations sociales: un domaine en expansion. In: JODELET, D. (org.). Les représentations sociales. $2^{\mathrm{a}}$ ed. Paris: Presses Universitaires de France.

KRAMER, Sônia, (1991). CIACs: falácias, equívocos e tentações. Educação e Sociedade, nº 40, p. 461-474.

LEAL, Maria Cristina, (1991). Práticas clientelísticas e recursos públicos para a educação de primeiro e segundo graus. Tese de doutorado. Faculdade de Educação da Universidade Federal do Rio de Janeiro.

LEONARDOS, Ana Cristina, (1990). Opportunities to learn academic skills in the brazilian public schools: a comparative case study. Tese de doutorado. Stanford University.

, (1991a). O CIEP como inovação educacional. Contexto e Educação, ano 6, n 22, p. 46-64.

, (1991b). Avaliação do desempenho de alunos de CIEP e de escola convencional: comparando o desenvolvimento de pensamento crítico. Relatório de Pesquisa. Rio de Janeiro: CAPES/UFRJ.

, (1992). Análise de discurso das produções acadêmicas de alunos de CIEP (representativo da proposta original) e de escola convencional. Relatório de Pesquisa. Rio de Janeiro: CAPES/UFRJ.

LIMA, Valdileia, (1988). CIEPs: a re-invenção da escola pública? Dissertação de mestrado. Faculdade de Educação da Universidade Federal Fluminense.

LOBO JR., Dácio, (1986). Sobre as relações entre as questões da educação e do populismo. Educação e Sociedade, n² 24, p. 48-60. , (1988). CIEPs: a impotência de um desejo pedagógico. Dissertação de mestrado. Faculdade de Educação da Universidade Federal Fluminense.

MAURÍCIO, Lúcia V., SILVA, Isabel, (1995). Avaliação externa 1993 e 1994. Carta 15: O novo livro dos CIEPs. Brasília: Senado Federal, p. 193-219.

MIGNOT, Ana Christina, (1988). CIEP: alternativa para a qualidade de ensino ou nova investida do populismo em educa- ção? Dissertação de mestrado. Faculdade de Educação da Pontifícia Universidade Católica do Rio de Janeiro.

MOUSSATCHÉ, Helena, (1998). A arquitetura escolar como representação social da escola. Tese de doutorado. Faculdade de Educação da Universidade Federal do Rio de Janeiro.

OLIVEIRA, Carlos Alberto, (1991). CIEP: modelos subjacentes de uma escola que está fazendo escola. Dissertação de mestrado. Faculdade de Educação da Universidade Federal do Rio de Janeiro.

PAIVA, Vanilda, (1985). O populismo e a educação no Rio de Janeiro: resposta a Darcy Ribeiro. Educação e Sociedade, $\mathrm{n}^{\circ} 22$, p. 134-137.

PARO, Vitor, FERRETI, Celso J., VIANNA, Cláudio P. et al., (1988a). A escola pública de tempo integral: universalização do ensino e problemas sociais. Cadernos de Pesquisa, $\mathrm{n}^{\circ}$ 65, p. 11-20.

(1988b). Viabilidade da escola pública em tempo integral. Educação e Sociedade, n 29, p. 86-99.

, (1988c). Escola de tempo integral: desafio para o ensino público. São Paulo: Cortez.

PERISSÉ, Vanda Lúcia S., (1994). Análise da evasão de alunos de um CIEP de segundo segmento do primeiro grau para escolas de horário parcial. Dissertação de mestrado. Faculdade de Educação da Universidade Federal do Rio de Janeiro.

RIBEIRO, Darcy, (1985). Pedagogia vadia. Educação e Sociedade, $\mathrm{n}^{\circ} 22$, p. 132-134. , (1986). O livro dos CIEPS. Rio de Janeiro: Bloch. , (1995). Balanço crítico de uma experiência educacional. In: RIBEIRO, Darcy. Carta 15: O novo livro dos CIEPs. Brasília: Senado Federal, p. 17-24.

TEIXEIRA, Anísio, (1994). Educação não é privilégio. $5^{\mathrm{a}} \mathrm{ed}$. Rio de Janeiro: Editora da UFRJ.

Recebido em outubro de 2003

Aprovado em maio de 2004 
self-formation, which allow them to

reflect on their practice, the creation of spaces for exchange and conviviality in which individuals can exercise criticality, creativity and a strengthening of the relations between practiceltheory/practice, promoting the autonomous and systematic exercise of their actions, knowledge and powers.

Key-words: adult and youth education; formation of teachers; between-places

Lúcia Velloso Maurício

\section{Literatura e representações da} escola pública de horário integral $\mathrm{O}$ artigo apresenta o confronto entre $\mathrm{o}$ que se depreende da literatura produzida entre 1983 e 2001 sobre a escola pública de horário integral e a representação social que usuários e trabalhadores construíram sobre este tema. Após análise temática da literatura pertinente, realizou-se pesquisa de campo em quatro Centros Integrados de Educação Pública (CIEP) de $1^{\mathrm{a}}$ a $4^{\mathrm{a}}$ série, localizados em bairros populares, para identificar a representação social construída por alunos, pais, professores e funcionários. Nem todas as questões colocadas pela literatura foram contempladas no campo. Entretanto, ficou evidenciada a existência de duas óticas distintas a respeito da função social desta escola e dos fatores mobilizadores para sua demanda. De um lado, a representação dos professores, centrada na necessidade do aluno como justificativa para essa escola, assemelha-se aos argumentos encontrados na literatura. De outro lado, a representação dos pais e alunos, centrada na satisfação, contempla as idéias de lazer, futuro e educação.

Palavras-chave: escola pública de horário integral; representação social; necessidade $x$ satisfação

\section{Literature and representations} concerning full-time public schooling This article compares the literature produced between 1983-2001 on full- time public schooling and the social representation that users and workers formed about it. After analysing the main themes of the relevant literature, four Integrated Centres of Public Education (CIEP) were selected, in working-class districts, in order to identify the social representations created by their students, parents, teachers and administrative staff.

Although some of the questions raised by the literature could not be verified, the research indicated the existence of two different social representations about the full-time public school and the demand for it. One of them was the teachers'view, based on the needs of children to justify the maintenance of these schools, which was similar to the arguments found in the literature. The other was the social representation of parents and school children and was formed around the notion of satisfaction, contemplating the ideas of leisure, future and education.

Key-words: full-time public school; social representation; needs $\mathrm{x}$ satisfaction

Eurize Caldas Pessanha, Maria Emília Borges Daniel e Maria Adélia Menegazzo

Da história das disciplinas escolares à história da cultura escolar: uma trajetória de pesquisa

Este texto reflete sobre a trajetória que o grupo de pesquisa Professores e Disciplinas Escolares da Universidade Federal de Mato Grosso do Sul vem percorrendo e sobre como, partindo de pesquisas sobre a história das disciplinas escolares, o grupo chegou ao estudo da história da cultura escolar. Para essa reflexão, são analisados os pressupostos do campo de investigação conhecido como "história das disciplinas escolares", conforme Chervel, e os conceitos de cultura e cultura escolar, de acordo com Wiliams, Forquin, Julia, Faria Filho, Viñao-Frago e Escolano. O artigo argumenta que a investigação sobre a cultura escolar de uma determinada escola pode conduzir à reconstituição da história da cultura escolar de uma cidade.

Palavras-chave: cultura escolar; currículo; disciplinas escolares

From the history of school subjects to the history of school culture: a research trajectory

This text is a reflection on the trajectory that a research group on "Teachers and School Subjects", from the Federal University of Mato Grosso do Sul, has been pursuing and on how it arrived at the study of history of school culture, starting from research into the history of school subjects. For this reflection we analyse presuppositions from the field of investigation known as "history of school subjects", according to Chervel, and concepts of culture and school culture, as posited by Williams, Forquin, Julia, Faria Filho, ViñaoFrago and Escolano. We argue that research into the school culture of a determined school can lead to the reconstitution of the history of school culture in a specific city.

Key-words: school culture;

curriculum; school subjects

Antonio Miguel e outros

A educação matemática: breve histórico, ações implementadas e questões sobre sua disciplinarização Este trabalho foi elaborado em tópicos autônomos para discutir a configuração da educação matemática como área de pesquisa e, num panorama histórico, expõe e analisa como têm sido implementados, efetivamente, esforços para sua consolidação no Brasil. A partir da apresentação de alguns elementos relativos à emergência e à organização da pesquisa em educação matemática no panorama internacional (D'Ambrósio), ele passa a esboçar as motivações e estran- 